\title{
Innovative Component of Modern Higher Education in the Republic of Kazakhstan
}

\author{
Nazym Stamgaliyeva, Yelena Feoktistova \\ Caspian State University of Technologies and Engineering Named after S. Yesenov, Aktau City, The Republic of \\ Kazakhstan \\ Email: naza stam@mail.ru, yelena976@gmail.com
}

Received 17 August 2014; revised 1 October 2014; accepted 17 October 2014

Copyright (C) 2014 by authors and Scientific Research Publishing Inc.

This work is licensed under the Creative Commons Attribution International License (CC BY). http://creativecommons.org/licenses/by/4.0/

c) (i) Open Access

\begin{abstract}
The paper considers modern conditions of education development in the Republic of Kazakhstan. Modern higher education in Kazakhstan is based mainly on the results of innovations as a science of innovations. The bases of the work of higher education institutions in Republic of Kazakhstan lie in the following strategic acts: Program of Enforced Industrial and Innovative Development of Kazakhstan, State Program of Education Development in Kazakhstan for 2011-2020. High schools have to form the whole system of universal knowledge, habits and skills, also self-activities and personal responsibilities of students that are key competencies, determining modern quality of education. It is necessary to introduce structural, institutional, organizational and economic changes in the system of higher education and as a result make new content of education, and design it in accordance with requirements of time and with the tasks of developing country. That is why today the realization of competence approach needs the support on international experience, by the necessary adaptation to traditions and demands of Kazakhstan.
\end{abstract}

\section{Keywords}

Innovations Oriented Specialists, Information and Communication Technologies, Electronic Establishment, Distant Education Technologies, E-Learning, Cooperative Learning

\section{Introduction}

Higher education in Kazakhstan is based mainly on the results of innovations as a science of innovations. The bases of the work of higher education institutions in Republic of Kazakhstan lie in the following strategic acts: Program of Enforced Industrial and Innovative Development of Kazakhstan, State Program of Education Development in Kazakhstan for 2011-2020. The objectives of Education Development Program are the improve- 
ment of its competitiveness, the development of human capital assets by means of providing quality education for the purpose of steady economic growth. New approaches require modern ideas and decisions based on creative plans, break-through projects, modernized school and university education systems. The ever developing society and education system are now characterized by life-long education, transition of schools and higher education institutions towards innovative activities, a new role of universities in the society life, upbringing and training of innovatively educated personnel, the orientation of the acquired knowledge on meeting the interests of individuals and society on the whole.

\section{Higher Education Quality and Significance}

Kazakhstan is on the way of filling the education with new quality and significance. State higher education institutions (HEI) enter brand new level of education and training younger generations. According to the transition of HEIs towards innovation activity as a task-oriented process of introduction of new quality elements and characteristics the following classification of HEIs has been worked out: state research universities, national higher education institutions, research institutes, universities, academies. A special position in the mentioned above classification will be taken by research university which is under the Republican State Law on Science is considered an institution implementing the government program of development of universities. It will also participate in applied scientific researches and other scientific and technical experiments and design engineering. The main objective of Research University is the integration of scientific activity and education process on all level of higher and post-graduate education. HEI of the kind will combine the traditions of classical university and innovations; it will be the embodiment of integration of academic values and entrepreneurial culture. The development of modern society is connected with innovations as a process of application of new means, taskoriented changes which introduce new stable elements into the environment and cause the transition of system from one condition towards another [1]. But not any invention can be referred to as an innovation and should be introduced. It is something dynamic, something that has future, contributes to progressive development and implies positive economic effect. On the modern stage of Kazakhstani higher education development innovations become a prevailing factor of its development. The ability to perceive innovations, determine the direction of innovation development allows a HEI to comply with the demands of the changing society and labor market. The university work changes from operation to development mode. The main aim of innovative HEI is training of innovative oriented specialists on the basis of progressive knowledge and teaching methods. The notion "innovative personnel" connected with innovative potential, motivation in professional activity under conditions of modern economic, high level of creativity, understanding of issues and finding off-grade solutions, working in team, knowing the competence rated in innovative economics.

The basis of training first-class specialists has always laid in quality education. Whereas the actual issue of linguistic didactics has been an issue of applying and practical implementing of knowledge of innovation educational technologies. Under this technology we consider a systematic approach for creating, applying and identifying the whole education process and acquiring knowledge including the technical and human resources and their interaction for the purpose of optimization of education forms [2]. The pedagogical innovation, or innovations in education, is referred to as an invention to pedagogical activity, specially projected or explored at random.

The world educational system now witnesses the implementation of information and communication technologies (ICT). The practical education of Kazakhstani system has also seen some changes defined as the "informatization of education". These changes include: creation of electronic libraries in HEIs, organization of study process with the application distant education technologies, opening of multimedia classrooms, creation of multilevel system of training and re-training of personnel in the field of information technologies. Introduction of electronic learning (e-learning) takes a special place in this field-learning with the help of information and communication technologies. New information technologies, multimedia and Internet technologies are used to improve the quality of education on account of improving the access to resources and services, as well as remote knowledge and mutual experience exchange. The main advantages of e-learning are connected with the expansion of accessibility and improvement of education quality. Educational services may be provided directly at the student's residence which is especially important for disabled people, socially vulnerable people and people living in remote villages.

The State Program on Education Development in Kazakhstan 2011-2020 highlights the basic directions of ac- 
tivity, which lay the bases of e-learning in our country. The aim of e-learning is provision of equal access for all participants of education process to better educational resources and technologies. The task of the program is to create conditions to introduce automatization of teaching process. 50\% of HEIs are expected to use e-learning systems by 2015, and 90\%-by 2020. Bakytzhan Zhumagulov, Minister of Education and Science of Republic of Kazakhstan said: "It is not an easy task, it requires a brand new methodology, technical and information bases. We must handle it" [3]. Caspian State University of technologies \& Engineering named after Sh. Essenov is one of the participants to introduce e-learning in the process of HEI management and teaching students. E-learning will improve the education quality; strengthen the integration with the environment since its usage helps to acquire knowledge more quickly and effectively. E-learning in itself is a set of methods, approaches and instruments of giving knowledge. E-learning helps to change the style of interaction between the teacher and student and consider the student as a central figure of the teaching process. The teacher becomes the organizer of the student's activity, defines the aims of education and creates the environment for the student's acquiring of knowledge. This is the mechanism of carrying out the idea of person-oriented education, oriented on the subject of education - the human being. The basis of person-oriented paradigm of education lies in understanding that besides the background knowledge and simple thinking process, modern life requires such traits of character which are necessary in every field of human activity. The aim is development of personal values in the process of education. Person-oriented education is not aimed at creating a personality with previously set traits, characteristics. The new conditions require the development of personal experience acquired in the process of studying. The implementation of e-learning will improve the education quality, effectiveness of education management, informational integration with the environment.

Information and communication technologies are an instrument for renewal and rethinking of the environment. According to the experts, we witness a new stage of social development and transformation of the society into an informational society, characterized by the formation of new relations between people. This is a new type of society emerging as a result of the development and convergence of information and telecommunication technologies. This is the society of knowledge which main factor for human well-being is the knowledge gained through free access to information and work competence. This is a society in which information exchange will not have any time, space or political boundaries, a society which will allow making better and sound decisions to improve the quality of life with the help of scientific data and knowledge.

This is a society, which, on the one hand, promotes the interpenetration of cultures, and on the other handopens up new opportunities for each community for self-realization [4]. The main characteristics of the information society will be the parameters that largely determine the steady progress of each state: the availability of information resources necessary for professional or personal activities that every member of society can obtain at any time, access to modern information and communication technologies, creation of advanced information infrastructure allowing to continuously updating information resources. Knowledge becomes a crucial condition for the development of the education system, which determines the emergence and strengthening of the education system throughout its life.

One of the characteristic features of the information revolution is the widespread use of mobile information technology, which refers to the use of a set of personal portable hardware, software and techniques and methods that allow to carry out all kinds of electronic search, storage, computer processing, the reproduction of text, audio, video and graphical data under the conditions of instant communication with the resources of the international computer and telephone networks.

E-learning technology occupying a niche in the global educational process is now being applied in Kazakhstan. It is included into the academic curriculum of higher education. It will involve people from geographically remote locations into the teaching and research activities. It helps to save time and money, provide interaction of students and teachers online and offline. It will enable participants to contribute to the educational process at any time. It enables teachers to implement copyright policies, placing their own versions of other teaching materials; it will provide an opportunity to involve other resources as well [5].

Nowadays special attention is paid to distance learning technologies which is intensively introduced in the universities of Kazakhstan. Great possibilities of distance learning are determined by a wide range of means for its implementation. They include educational books - copies in paper and electronic versions of textbooks, teaching manuals, directories, online training manuals, computer training systems, training and information materials made in the audio and video mode, remote laboratory workshops, fitness center with remote access, the database with remote access, digital libraries with electronic access, learning tools based on expert training sys- 
tems, training means based of geographic information systems, learning tools based on virtual reality. The central place of distance learning is taken by individual activity of students on acquiring knowledge through various sources of information. The student is involved in active work with no limits to obtaining mechanical knowledge. It provides the application of knowledge to solve life problems. Organization of student's individual work in the network presumes the usage of the latest teaching technologies relevant to the features of this form of training aimed at disclosure of intellectual and creative potential of each student. Distance learning is based on the active interaction of students with teachers and the other partners. The control is based on immediate feedback, automatic control, delayed control.

Doubtless advantages of the ICT do not down-grade the importance of other technologies introduced and applied in Kazakhstani higher education. One of the most significant places is taken by the technologies concerning the development and improvement the individualities involved in the pedagogical process. Individualoriented technologies are relevant since they direct teachers towards the unique nature of human beings. The rapidly developing technology of cooperative learning is also distinguished among the various directions. The main idea of cooperative learning is to study in a team, but not to perform a task jointly.

Cooperative learning in general has no legal and executive instruments, but its ideas are included into almost all modern educational technologies. Cooperative learning, learning in small groups is technologies which have been used in teaching for many years. Achievements of scientists and experts from around the world have confirmed its validity and efficiency. Cooperative Education reflecting person-oriented approach with different options is considered in the global pedagogy as the most successful alternative to traditional methods of school and higher education.

Student Team Learning (STL), Jigsaw, Learning Together and group research work of students are the main options for collaborative learning. Principles of modern innovative education comply with the ideas of cooperative learning. Productive cooperative activity and cooperative learning determine the formation of the necessary forms, methods of working to meet the strategic goals of the development of our country, to build an innovative economy of industrial and intellectual development of country ready to enter and compete in the technology marketplace.

Cooperative learning has the following forms of teaching: "one to one", "one to many", "many to many". Methods of individualized learning "one-one" in modern education develops not only through traditional individual work of students with the teacher or another student, but through the use of telephone, voicemail and e-mails, so-called television-teaching mediated by computer networks as well.

Based on innovative technologies the teaching model of "one to many" is now developing when in the working process video, audio, television lectures, the so-called "e-lectures" (electronic lectures), are used. E-lectures may contain not only the traditional texts but selection of materials that may serve as the basis for further work, for example, discussions on definite issues.

A special interest has been attached to the usage of the "many to many" pedagogical model of teaching. The age of telecommunication technologies witnesses the increasing intensity of using these techniques. They are based on online interaction of students which serves as a source of obtaining and processing knowledge. A special place among the forms of work is occupied by computer conferencing which allows its participants to exchange messages in a synchronous and asynchronous mode. All this allows using the following productive forms of work: role play, debates, brainstorming, Delphi method, projects, etc.

Another system related to person-oriented educational technologies is defined as the contextual learning. This technology is based on an alternative to authoritarian teaching when the student performs as the object of the impacts associated with the domination of teacher training over students' learning activity. Education material in the context learning, as well as in traditional learning, is presented in the form of educational texts as symbolic systems and it acts as the information to be learned. A distinctive feature of symbolic and contextual learning is structured information in the form of tasks and problematic situations which projects the problems of future professional activity. According to the scientists, the application of symbolic and contextual training highlights the basic directions of the trainees' activity: activities of the academic type (the learning activities in itselflectures, seminars and individual work), quasi-professional activities (business games, game forms of activities), educational and professional activities (scientific research, practices, graduation paper).

The following types of work are considered as the transition from one form to another: laboratory practical lessons, simulation projects, analysis of specific work situations, role-playing, special courses and seminars [3]. The leading methods of symbolic and context learning are active methods of recreating the social content of fu- 
ture professional activity.

Other technologies that introduce innovative elements into the educational process are also used in higher education practice; one may distinguish programming, modular training, suggestive technology, interactive methods, etc. Universities readily go forward in modernizing its activities with due respect to the traditions of previous education systems.

Analysis of the development of world and national education systems shows that the nature of learning sees changes in correspondence to the global education trends. An important feature of modern university education is its focus on preparing students for the changes in study and life situations. Innovative component of modern university education is largely based on the distinction between two types of education: "supportive" and "innovative".

The idea of the basic types of education was introduced in the late 70s of the XX century in the report to the Club of Rome "There is no limit for learning" Supporting education is defined as a process and outcome of educational activities that is aimed at maintaining and renewal of the existing culture, social experience. This type of education ensures the continuity of social and cultural experience; it is the type to dominate in the secondary and higher education for many years.

Innovative Teaching is a process and result of the educational activity that promotes innovative changes in the existing culture and social environment. This type of education stimulates an active response to problematic situations an individual or society may face. The present approach gives a clearer view on the importance of didactic searches (Electronic Library, 2011).

The innovative approach to HEI education in many ways provides all participants an equal access to the best educational resources and technologies. This is one of the ways to achieve a high level of quality in higher education in accordance with the State Program for the Development of Education in Republic of Kazakhstan for 2011-2020 years to meet the needs of labor market, tasks of industrial and innovative development of individuals and country on the whole which will comply with the best international practices in education.

After entering the Bologna process in March 2010, Kazakhstan was the first Central Asian State to enter the European educational system. Our country accumulates positive experience in education and applies the achievements of foreign higher education. The reason why our country integrates the national education system with the European system is to ensure that Kazakhstan's higher education comply with the international standards. This is a step towards enhancing the competitiveness of the graduates of our universities.

One of the principal of innovative advantages of the Bologna process is the mobility of teachers and students i.e. the movement of students or teachers at a particular academic period (semester or academic year) into an institution of higher education within the country or abroad to study or conduct researches with the obligatory credit transfer.

The concept of academic mobility of students of higher educational institutions implies that Kazakhstan can succeed in achieving a high level of quality education only if it is possible to use the abilities and capacities of its citizens, if it will fully participate in the process of life-long education as well as in expanded participation in higher education. Result-oriented education and mobility will help students to develop competence necessary in changing labor market which will help specialists to become active and responsible citizens.

Strategic goals of higher education include the provision of competitive educational institutions and their graduates, training the new formation specialists with strong fundamental competence combined with mobility, creativity, initiative, adaptability to changing conditions of life, competence in the field of innovative economy, the provision of individual opportunities in the choice of education direction, life-long education, the formation of students' ideological position adequate to modern standards of living.

Innovative component of higher education implies new approaches to the management of the university, new solutions, new innovative management. In order to strengthen the innovative status of higher education institutions structural reorganization is carried out. It is aimed at obtaining results that are adequate to drastic and ambitious plans. Thus, Caspian State University has created departments designed to embody the idea of the forced development of the university: Department of Innovative Technologies and Department of Academic Mobility.

The objective of Department of Innovative Technologies is implementation of innovative technologies to the educational process and university administration; participation in the training of the innovative staff appropriate for the strategic aim of Kazakhstan Republic to enter the number of the most competitive countries in the world. The aim of its activity is to improve the effectiveness of study process and university functioning. The main direction of activities are as follows: strategic orientation of Caspian State University to the innovative way of de- 
velopment, generalization and distribution of information regarding innovative educational technologies, creation of the data base in the sphere of innovation, implementation of innovative educational programs and technologies in the process of education, assistance in implementation of e-learning and m-learning technologies in the educational process, participation in the development and expert evaluation of educational-methodical documentation, innovative management.

The mission of Department of Academic Mobility covers the organization of mobility at the university, the provision of students, undergraduates and young scientists with an opportunity to continue their education or acquire research experience abroad by participating in short-term educational or research program. The purpose of the work is the development of programs of academic mobility that acts as a definite indicator of the quality of education, the improvement of understanding between different peoples and cultures, and the education of younger generations prepared to live and work in the international information community.

Main activities are as follows: the development of scientific and educational links of Caspian State University, facilitating students and teaching staff exchange including the possibility of internship for a specified period, the participation in international scientific and educational programs, the organization and conduction of exchange programs with foreign partner-universities, the organization of summer semesters at the university.

\section{Conclusions}

Modern notion of innovations includes a wide range of concepts that go beyond pedagogical innovations, nontraditional lessons and non-standard forms of educational work. Innovative component of modern university education in Republic of Kazakhstan is associated with the integration of scientific activities and educational process at all levels of education, the development and implementation of standards of educational programs to foster a dynamic development of scientific-technological complex of the country and its human resources.

The strategic goal of this work is the transition of national educational organizations on the world level, ensuring the competitiveness of professional staff. The XXI century as a century of innovation and mobility offers ample opportunities for new approaches giving a way to solve complex problems and achieve strategic objectives.

\section{References}

[1] Griov, V. and Gruzinov, V. (2004) The Notion of Innovation. www.inventech.ru

[2] Kukushina, V.S. (2011) A Series of Pedagogical Education. Rostov Science, 5.

[3] Jumagulov, B. (2011) Objectives for the Implementation of the President N. Nazarvayev's Message to the People of Kazakhstan and State Program of Education for 2011-2020. Higher Education in Kazakhstan, 1, 35.

[4] Tikhomirov, N.V. and Tikhomirov, V.P. (2011) The Development of E-Learning Industry the Situation in Russia and Worldwide Experience. Foreign Experience of Distance Education. MESI Materials, Karaganda, 18.

[5] Kuvshinov, S. (2007) M-Learning as a New Reality Education. Higher Education in Russia, 8, 76. 
Scientific Research Publishing (SCIRP) is one of the largest Open Access journal publishers. It is currently publishing more than 200 open access, online, peer-reviewed journals covering a wide range of academic disciplines. SCIRP serves the worldwide academic communities and contributes to the progress and application of science with its publication.

Other selected journals from SCIRP are listed as below. Submit your manuscript to us via either submit@scirp.org or Online Submission Portal.
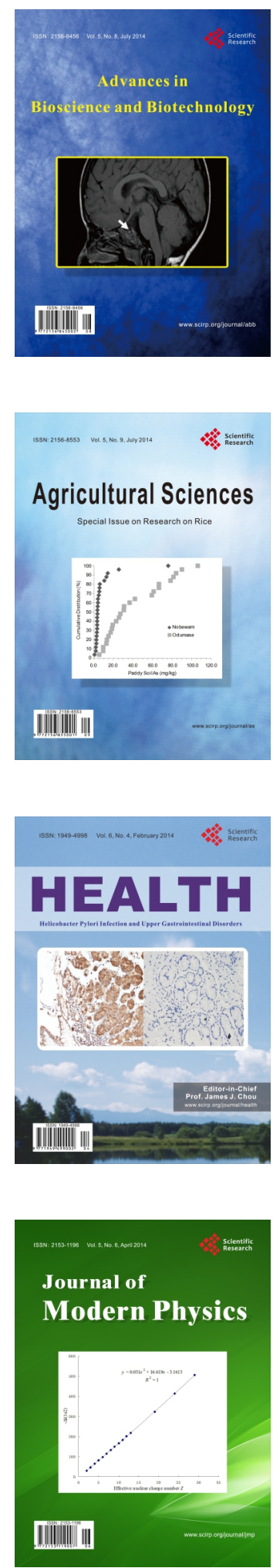
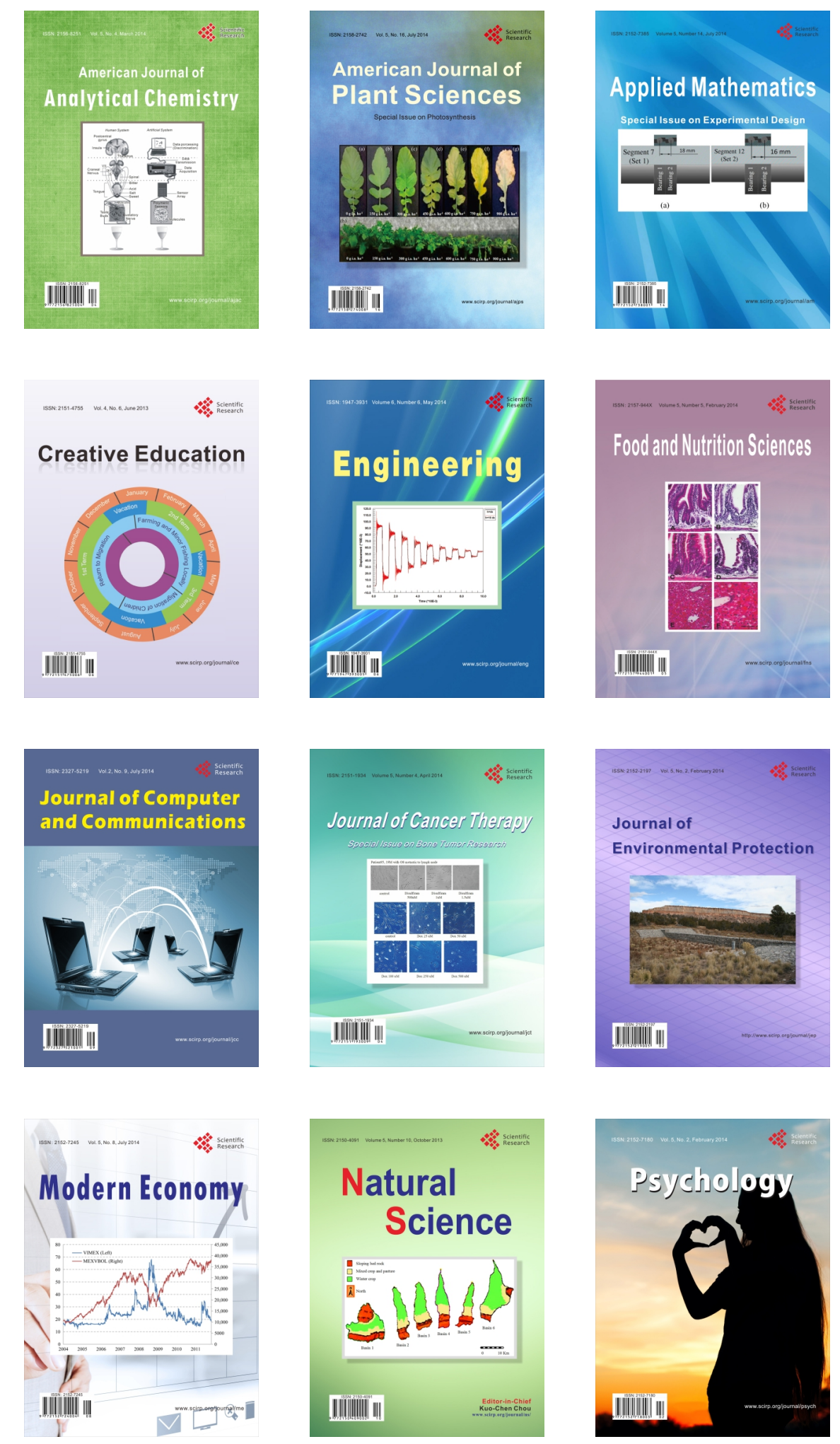